\title{
SOLAR-BIOMASS HYBRID SYSTEM; PROPOSAL FOR RURAL ELECTRIFICATION IN BANGLADESH
}

\author{
Md. Raju Ahmed ${ }^{1}$, Subir Ranjan Hazra ${ }^{1 *}$, Md. Mostafizur Rahman ${ }^{1 * *}$ and Rowsan \\ Jahan Bhuiyan $^{1 * * *}$ \\ ${ }^{1}$ Department of Electrical and Electronic Engineering \\ Dhaka University of Engineering \& Technology (DUET), Gazipur, Bangladesh \\ mrahmed@duet.ac.bd, "hsubir@yahoo.com, ${ }^{* *}$ mostafiz.tbl@gmail.com, \\ ${ }^{* * *}$ rowsan.jahan@yahoo. com
}

\begin{abstract}
Energy is one of the essential requirements to alleviate poverty and socioeconomic advancement. Most of the rural area is not under the national grid; therefore, electrification in rural area is the crying need of Bangladesh. Government of the People's Republic of Bangladesh has issued its vision to bring the entire country under electricity service by the year 2030. The reserve of fossil fuel is diminishing; also the price of fuel is increasing throughout the world. Environmental pollution is another important issue. Green energy is current demand for the existence of future world. For that reason, reducing carbon emission and meeting energy demands are the main topologies to plan energy systems. As Bangladesh is an agricultural based country, biomass resources are available here and there is also good prospect of solar energy. In this paper, a solar-biomass hybrid system is proposed for electrification of rural area in Bangladesh.
\end{abstract}

\section{KEYWORDS}

Biomass, Solar PV, Hybrid System, Gasification, HOMER, Power Generation

\section{INTRODUCTION}

Energy is the basic requisite for the development of a country and electrical energy is superior to all other forms of energy. Bangladesh has a population of 161 million (or 29 million households). Fifteen million of them are concentrated in rural areas. Rural electrification requires a number of conditions. Due to less specific population density, low energy demand and undeveloped rural economics, rural electrification penetration rate is poor. Successful rural electrification and long term accomplishment is badly needed. Bangladesh has good potential of solar and biomass resources.

The earth receives 175 petawatts (PW) of incoming solar radiation (insolation) at the upper atmosphere. Approximately $30 \%$ is reflected back to space while the rest is absorbed by clouds, oceans and land masses. The spectrum of solar light at the Earth's surface is mostly spread across the visible and near-infrared ranges with a small part in the near-ultraviolet. The total solar by the Earth's atmosphere, oceans and land masses is approximately 3,850,000 exajoules (EJ) per year. The insolation in Bangladesh varies from $3.8 \mathrm{kWh} / \mathrm{m}^{2} /$ day to $6.4 \mathrm{kWh} / \mathrm{m}^{2} /$ day at an average of $5 \mathrm{kWh} / \mathrm{m}^{2} /$ day. These indicate that there are good prospects for solar thermal and photovoltaic application in the country. Bangladesh is an agricultural based country and available biomass is

DOI : 10.14810/elelij.2015.4101 
mainly of agricultural residues like rice husk and rice straw from rice plants, sugarcane, jute stick, residues from wheat, potato, oilseeds, spices etc. In addition to the agricultural wastes the other resources are dry materials such as dry wood, dried leaf, charcoal, coconut shells, animal dung etc. Biomass fuel supply usually comes from main three sources viz. Crop residues, animal dung and trees [1]. The percentage of different traditional energy were as follows: cow-dung $20.4 \%$, jute stick $7.5 \%$, rice straw $11.6 \%$, rice husk $23.3 \%$, bagasse $3.2 \%$, fire wood $10.4 \%$, twigs and leaves $12.5 \%$, and other wastes $11.1 \%$ [2]. So, for lightning the rural area, in this paper we tried to develop an optimal system from the practical view point. HOMER, software has been used to expose combined cycle with biomass and solar resources.

Input information to be endowed with HOMER comprises: primary load, solar and biomass resources, cost, constraints, controls etc. The software focused on an optimal configuration to meet the desired electric loads. To design the most favorable systems HOMER performs the thousands of hourly simulations and it performs sensitive analysis also.

\section{HYBRID SYSTEM}

In this analysis, we have designed the hybrid renewable system with biogas generator. Here, solar photovoltaic panel is used as renewable resource and biogas is produced from biomass sources. The hybrid system consists of electric loads, solar resources, biomass resources and system components such as PV, generator, battery, and converter [3]. Figure-1 shows the biogas hybrid solar system.

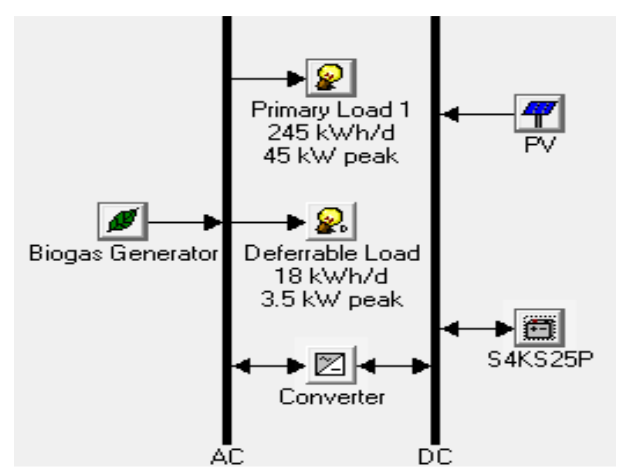

Figure 1. Hybrid energy renewable system

\subsection{Electric Load}

In this study a community of 100 households and 10 shops has been considered of a village near the Barisal city, Bangladesh. The load is based on 3 energy efficient lamps (15 W each), on an average 1 ceiling fan $(100 \mathrm{~W})$, and 1 television $(70 \mathrm{~W})$ for each family and 2 energy efficient lamps (15 W each), 1 fan $(100 \mathrm{~W})$ and overall 2 refrigerators $(1.2 \mathrm{kWh} /$ day each) for shops. Also, 5 refrigerators $(1.2 \mathrm{kWh} /$ day each) and 5 pumps $(150 \mathrm{~W}$ each) are considered among the residential. Load data are synthesized by specifying typical daily load profiles and adding some randomness of $10 \%$ daily. These scaled up the annual peak load to $45 \mathrm{~kW}$ and primarily load $245 \mathrm{kWh} /$ day and deferrable load $18 \mathrm{kWh} /$ day. Figure- 2 represents the daily load from November to February and Figure-3 contains the daily load profile from March to October. 
Electrical and Electronics Engineering: An International Journal (ELELIJ) Vol 4, No 1, February 2015

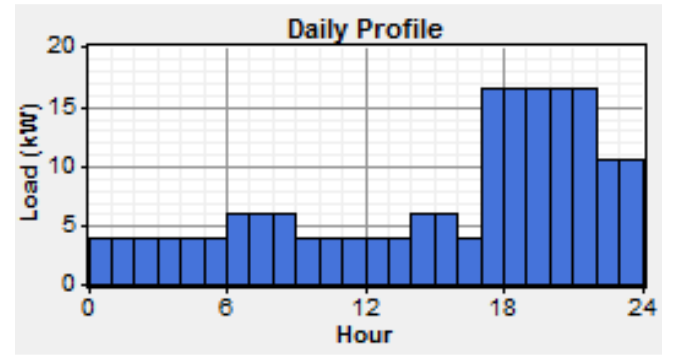

Figure 2. Load profile of a day (November-February)

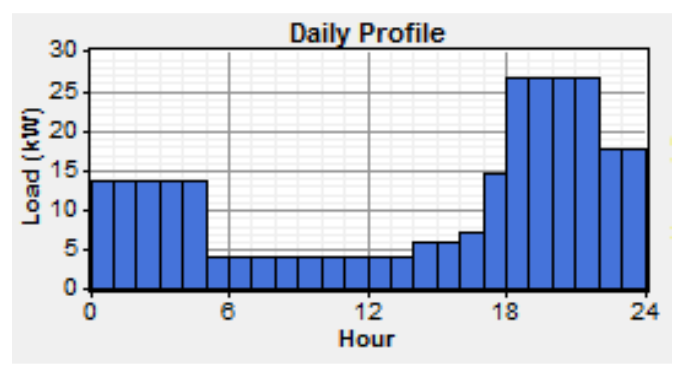

Figure 3. Load profile of a day (March-October)

\section{RENEWABLE ENERGY RESOURCES}

\subsection{Solar Resource}

Bangladesh has good prospects of solar photovoltaic generation. The average insolation in Bangladesh is $5 \mathrm{kWh} / \mathrm{m}^{2} /$ day. In this analysis, monthly average global radiation data has been taken from NASA (National Aeronautics and Space Administration) to estimate the generation of solar system. Solar data at Barisal (Latitude: 22.75, Longitude: 90.36) in Bangladesh is presented graphically by using HOMER software in Figure 4. Homer use the solar resources input to calculate the PV array power. And, the synthesized data is obtained by putting the longitudinal and latitudinal value in HOMER software.

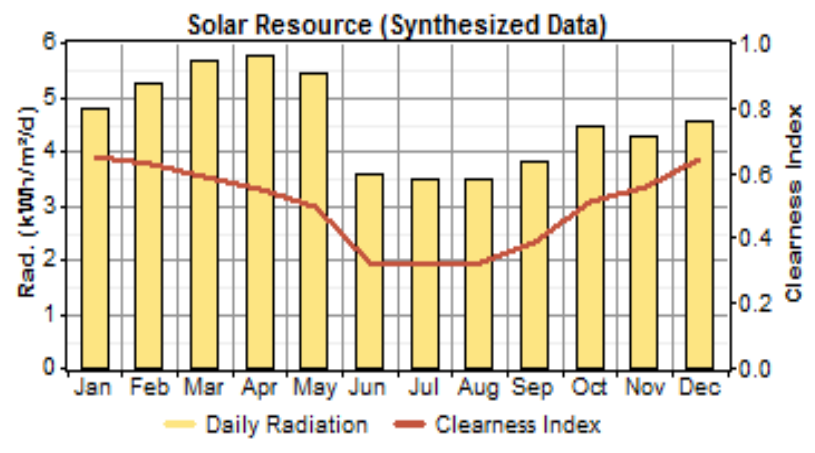

Figure 4. Solar Radiation data throughout the year 


\subsection{Biomass Resources}

Biomass is the oldest source of energy known to humans. The term biomass encompasses a large variety of materials, including wood from various resources, agricultural residues, and animal and human waste. Bangladesh is an agree-based country and main sources of biomass are agricultural residues. And in villages, mainly in Barisal, cow is still utilized for plowing land and farming. So, animal dung is available in resourceful amount.

Biomass contains stored energy. That's because plants absorb energy from the sun through the process of photosynthesis. When biomass is burned, this stored energy is released as heat.

Many different kinds of biomass, such as wood chips, corn, and some types of garbage, are used to produce electricity. Some types of biomass can be converted into liquid fuels called biofuels that can power cars, trucks, and tractors. Leftover food products like vegetable oils and animal fats can create biodiesel, while corn, sugarcane, and other plants can be fermented to produce ethanol.

More than 25000 bio gas plants are already set up in Bangladesh and they are mainly family sized and used only for cooking purposes. But, we need to focus to use this biomass energy for rural electrification. And that will be helpful for our economic advancement.

\subsubsection{Gasification}

Gasification of biomass has been known as one of the effective technology options for the utilization of this renewable energy resource. Gasification is the process of converting solid fuels into a combustible gas mixture with a controlled amount of oxygen and/or steam; this is accomplished by reaction of the material at high temperature (more than $700^{\circ} \mathrm{c}$ ). The resulting gas mixture is called syngas or producer gas. The power delivered from gasification of biomass and combustion of the resultant gas is considered to be a source of renewable energy. The calorific value of this gas varies between 4.0 and $6.0 \mathrm{MJ} / \mathrm{Nm}^{3}$ or about 10 to 15 percent of the heating value of natural gas [2][4]. The process of generation of electricity from biomass is illustrates in Figure 5.

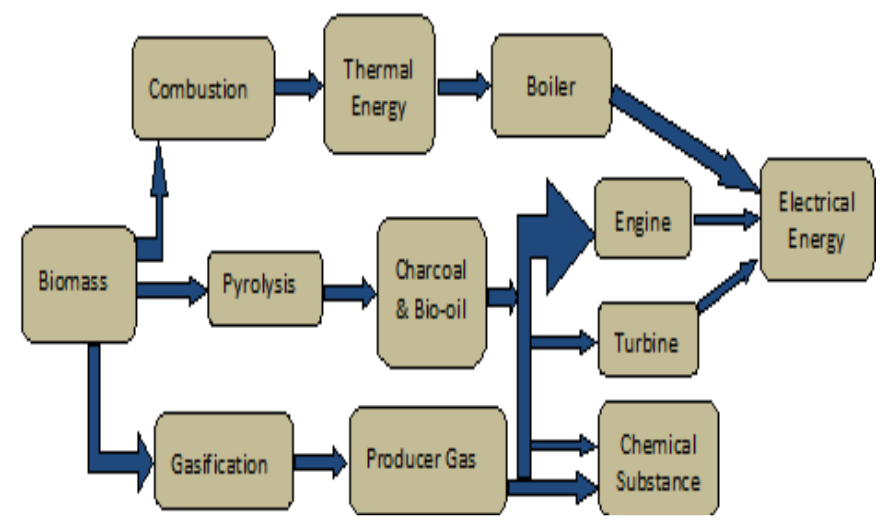

Figure 5. Biomass Conversion into Energy

The three different stages of total gasification produces are:

1) Gasification process starts as auto thermal heating of the reaction mixture.

2) In the second stage, combustion gases are pyrolysis by being passed through a bed of fuel at high temperature. 
3) Initial products of combustion, carbon dioxide $\left(\mathrm{CO}_{2}\right)$ and $\left(\mathrm{H}_{2} \mathrm{O}\right)$ are reconverted by reduction reaction to carbon monoxide $(\mathrm{CO})$, hydrogen $\left(\mathrm{H}_{2}\right)$ and methane $\left(\mathrm{CH}_{4}\right)$.

Biomass gasification is an alternative option of thermal biomass utilization for the production of heat and power based on biomass. Within the last 20 years several different gasification technologies were developed and demonstration plants were realized. Based on the experience from these demonstration plants the gasification technologies were further developed. Gasification plants consist of several process steps, which are shown in figure 6. The solid biomass fuel delivered needs to be adjusted (fuel conditioning and handling) to the fuel characteristics (particle size, water content) required for the gasification process. The conditioned fuel enters the gasification process, which produces raw product gas. The raw product gas needs to be cleaned in order to achieve the product gas quality needed for further utilization. The cleaned product gas is used for the production of electric power, heat and fuel based on different technologies.

During the thermo-chemical biomass gasification process solid biomass is cracked by thermal energy and a fumigator and converted into a product gas. The product gas is cleaned and used for the production of heat and power.

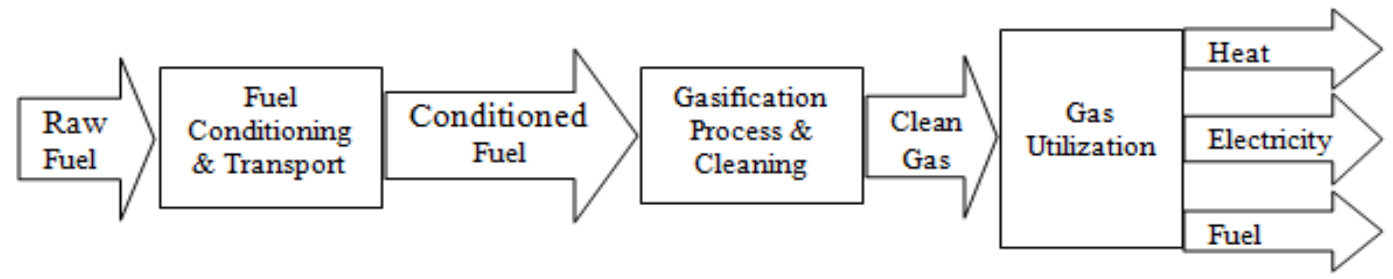

Figure 6. Basic process steps of a biomass gasification plant

\subsubsection{Conversion to Electricity}

Theoretically, biogas can be converted directly into electricity using a fuel cell. In most cases, biogas is used as fuel for combustion engines, which convert it to mechanical energy, powering an electric generator to produce electricity.

Appropriate electric generators are available in virtually all countries and in all sizes. The technology is well known and maintenance is simple. In most cases, even universally available 3phase electric motors can be converted into generators.

Gas turbines are occasionally used as biogas engines, especially in the US. They are very small and can meet strict exhaust emissions requirements. Small biogas turbines with power outputs are available on the market, but are rarely used for small-scale applications in developing countries as they are expensive. Furthermore, due to their spinning at very high speeds and the high operating temperatures, the design and manufacturing of gas turbines is challenging and maintenance requires specific skills.

External combustion engines such as Stirling motors have the advantage of being tolerant of fuel composition and quality. They are, however, relatively expensive and characterized by low efficiency. Their use is therefore limited to a number of very specific applications. In most commercially run biogas power plants today, internal combustion motors have become the standard technology either as gas or diesel motors. 


\subsubsection{Energy Generation by Using Cow Dung}

Several types of gasifier e.g. fixed bed updraft and downdraft gasifier, fluidized bed gasifier and bubbling bed gasifier are available in the existing market with different sets of pros and cons. However, the downdraft gasifier is a comparatively cheap and gasification in this type of gasifier can produce a product gas with very low tar current [4].

All the collected cow dung is fed into an anaerobic digester. The digester is built to hold 21 days of farm waste. Bacteria convert the waste into various products, one of which is methane gas. Gas produced by the bacteria builds up the pressure in the concrete vessel, and a pipe delivers the biogas to a modified natural gas engine.

The biogas fuels the engine, which in turn spins an electric generator to create electricity. Waste heat from the engine is used to keep the digester warm and offsets fuel purchase on the farm.

One cow's waste can produce enough electricity to light two 100-watt light bulbs for 24 hours a day. The energy is fed onto the electrical system for distribution to customers. Cow dung gas is 55-65\% methane, 30-35\% carbon dioxide, with some hydrogen, nitrogen and other traces. Its heating value is around 600 B.T.U. per cubic foot. Cow dung slurry is composed of 1.8-2.4\% nitrogen $\left(\mathrm{N}_{2}\right), 1.0-1.2 \%$ phosphorus $\left(\mathrm{P}_{2} \mathrm{O}_{5}\right), 0.6-0.8 \%$ potassium $\left(\mathrm{K}_{2} \mathrm{O}\right)$ and $50-75 \%$ organic humus.

About one cubic foot of gas may be generated from one pound of cow manure at around $28^{\circ} \mathrm{C}$. This is enough gas to cook a day's meals for 4-6 people in Bangladesh. About 1.7 cubic meters of biogas equals one liter of gasoline. The manure produced by one cow in one year can be converted to methane, which is the equivalent of over 200 liters of gasoline.

Gas engines require about $0.5 \mathrm{~m}^{3}$ of methane per horsepower per hour. Some care must be taken with the lubrication of engines using solely biogas due to the "dry" nature of the fuel and some residual hydrogen sulphide; otherwise these are a simple conversion of a gasoline engine.

Power generation by using cow dung consist of several process steps, which are shown in figure 7. First, cow dung is stored in biogas digester and produced gas in gasification process in cleaned and supplied it to syngas engine to produce electricity.

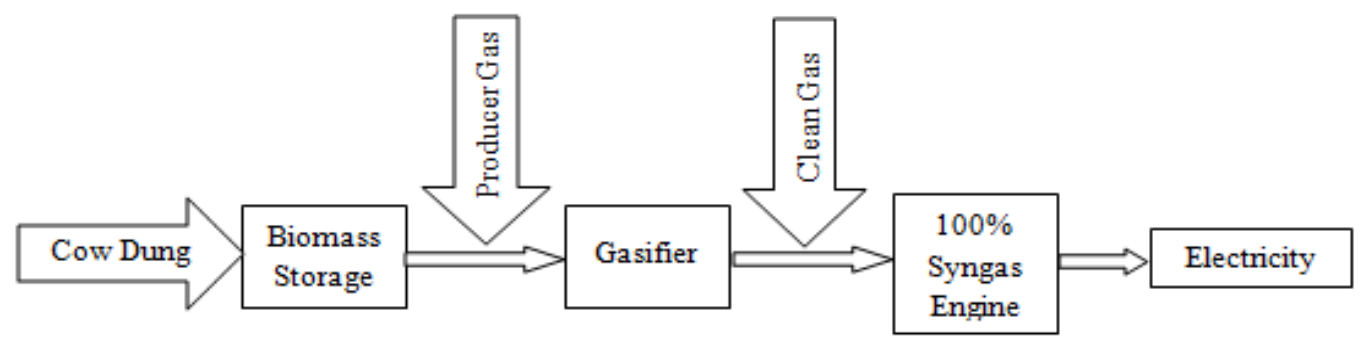

Figure 7. Electricity Generation by cow dung gasification

\section{SYSTEM COMPONENTS}

In this analysis, the major components are PV panels, biogas disaster, bio fuel generators, batteries, and converters. For economic analysis, the number of units to be used, capital cost, replacement and O\&M costs and operating hours to be defined in HOMER in order to simulate the system. 


\subsection{Solar Photovoltaic}

Sun rays are available with prosperity in Barisal, Bangladesh. Lots of solar home system has been installed. But, there is no set up yet established for off grid networking. In this research, solar photovoltaic is used with biogas generation for the establishment of a hybrid system. Solar system cost consists of cost with cables and charge controllers. It's known to me by analysing present market; cost of PV panel with set up cost Tk. 75000 for $1 \mathrm{~kW}$ generation. Various costs are represented in Table 1 and cost is considered in BDT. Life time has been taken 25 years and 25 kW PV modules are considered.

Table 1. PV cost assumption and technical parameters

\begin{tabular}{|l|c|c|}
\hline \multicolumn{1}{|c|}{ Parameter } & Unit & Value \\
\hline Capital Cost & BDT/W & 75 \\
\hline Replacement Cost & BDT/W & 66 \\
\hline Operating \& Maintenance Cost & BDT/Yr & 100 \\
\hline Lifetime & Years & 25 \\
\hline Derating factor & Percent & 80 \\
\hline Slope & Degree & 22.566 \\
\hline Tracking System & No tracking System & 0.05 \\
\hline \multicolumn{2}{|c|}{} \\
\hline
\end{tabular}

\subsection{Generator}

In this research, two set of $10 \mathrm{~kW}$ biomass generators are considered to find out the most cost effective system. The main reason of using to fulfil the energy demand in peak hour both for winter and summer season and also meet the terms of backup requirements. As biomass resource is available in prosperity, fuel cost is considered zero. The main cost is considered for biogas generation procedure and biogas power generator. . To produce $1 \mathrm{KW}$ electricity from biomass, $\$ 1200$ is required including plant cost and generator cost, i.e. about BDT 9600000 is required in this purpose [5]. Digester lifetime is considered for 8 years and fuel curve slope and intercept are taken as 0.05 and 0.33 respectively [6]. Different costs and parameters are given in Table 2.

Table 2. Cost and parameter of Biogas generator

\begin{tabular}{|l|c|c|}
\hline \multicolumn{1}{|c|}{ Parameter } & Unit & Value \\
\hline Capital Cost & BDT/kW & 96000 \\
\hline Replacement Cost & BDT/kW & 67200 \\
\hline Operating \& Maintenance Cost & BDT/Yr & 50 \\
\hline Lifetime & Hours & 35000 \\
\hline Load factor & Percent & 15 \\
\hline
\end{tabular}

\subsection{Battery}

Batteries are used to store the solar photovoltaic output. In rural area like our proposed are, where most of the power is used after day time. So, main target of our system is to store energy at day time and discharge the stored energy after evening. So, batteries are used following through charge controller. Also, a dump load is used for the purpose of removing excess charge and preventing system damage. In this system, the Surrette 4KS25P storage batteries are utilized [7]. The specifications and different costs of batteries are shown in Table 3. 
Electrical and Electronics Engineering: An International Journal (ELELIJ) Vol 4, No 1, February 2015

Table 3. Battery cost assumption and technical parameters

\begin{tabular}{|l|c|c|}
\hline \multicolumn{1}{|c|}{ Parameter } & Unit & Value \\
\hline Nominal Voltage & volt & 2 \\
\hline Nominal Capacity & Ah(kWh $)$ & $800(1.6)$ \\
\hline Maximum Charge Current & A & 162 \\
\hline Round-trip efficiency & Percent & 86 \\
\hline Minimum State of Charge & Percent & 30 \\
\hline Capital Cost & BDT/kWh & 7000 \\
\hline Replacement cost & BDT/kWh & 6000 \\
\hline Operating \& maintenance Charge & BDT/kWh/yr & 50 \\
\hline
\end{tabular}

\subsection{Converter}

Converter converts the dc power to ac power. As, most of the home appliances are operated in ac, dc generation from the PV array is converted to ac following through a controller. In this .proposed system, $25 \mathrm{~kW}$ converters are considered for optimum solution. The details of converter cost assumption and different parameters are given in Table 4.

Table 4. Converter cost assumption and technical parameters

\begin{tabular}{|l|c|c|}
\hline \multicolumn{1}{|c|}{ Parameter } & Unit & Value \\
\hline Capital Cost & BDT/kW & 15000 \\
\hline Replacement Cost & BDT/kW & 10000 \\
\hline Life time & Years & 15 \\
\hline Efficiency & Percent & 90 \\
\hline Rectifier Capacity & Percent & 95 \\
\hline Rectifier Efficiency & Percent & 85 \\
\hline
\end{tabular}

\subsection{System Control Parameters}

We have tried to design an off grid system in remote location. Bangladesh government declare target to cover all areas in between 2030. So, with considering caution factor, we have considered the project life time 25 years. Other consideration and parameters like System control parameters and various constraints are given in Table 5 .

Table 5. System control parameters and constraints

\begin{tabular}{|l|c|}
\hline \multicolumn{1}{|c|}{ Parameter } & Value \\
\hline Percent of annual peak load & 0 \\
\hline Percent of hourly load & 10 \\
\hline Percent of hourly solar output & 0 \\
\hline Maximum Unreserved energy & $0(\%)$ \\
\hline Maximum renewable fraction & 0 to $100 \%$ \\
\hline Maximum battery life & N/A \\
\hline Maximum annual capacity shortage & 0 to $1 \%$ \\
\hline
\end{tabular}




\section{RESULTS AND DISCUSSION}

The optimal systems performance analysis has been carried out by using HOMER software. In the results, numerous alternative feasible hybrid set-ups with different levels of contribution by the renewable resources were obtained. The optimized result is calculated for specific solar irradiation $4.67 \mathrm{kWh} / \mathrm{m}^{2} / \mathrm{d}$. The hybrid system encompass of $25 \mathrm{~kW} \mathrm{PV}$ array, two $10 \mathrm{~kW}$ generator and 75 storage batteries with $25 \mathrm{~kW}$ converter is economically more feasible with a total net present cost (NPC) of 12,469,464 taka and minimum cost of energy (COE) of tk.10.183/kWh. Optimized result is represented in Figure 8. Here, we calculated the result taking the annual capacity shortage 0 to $1 \%$. As there is no fuel cost for generation like diesel or gas, COE [8] energy is low comparing to PV-diesel hybrid system that was analyzed in [9].

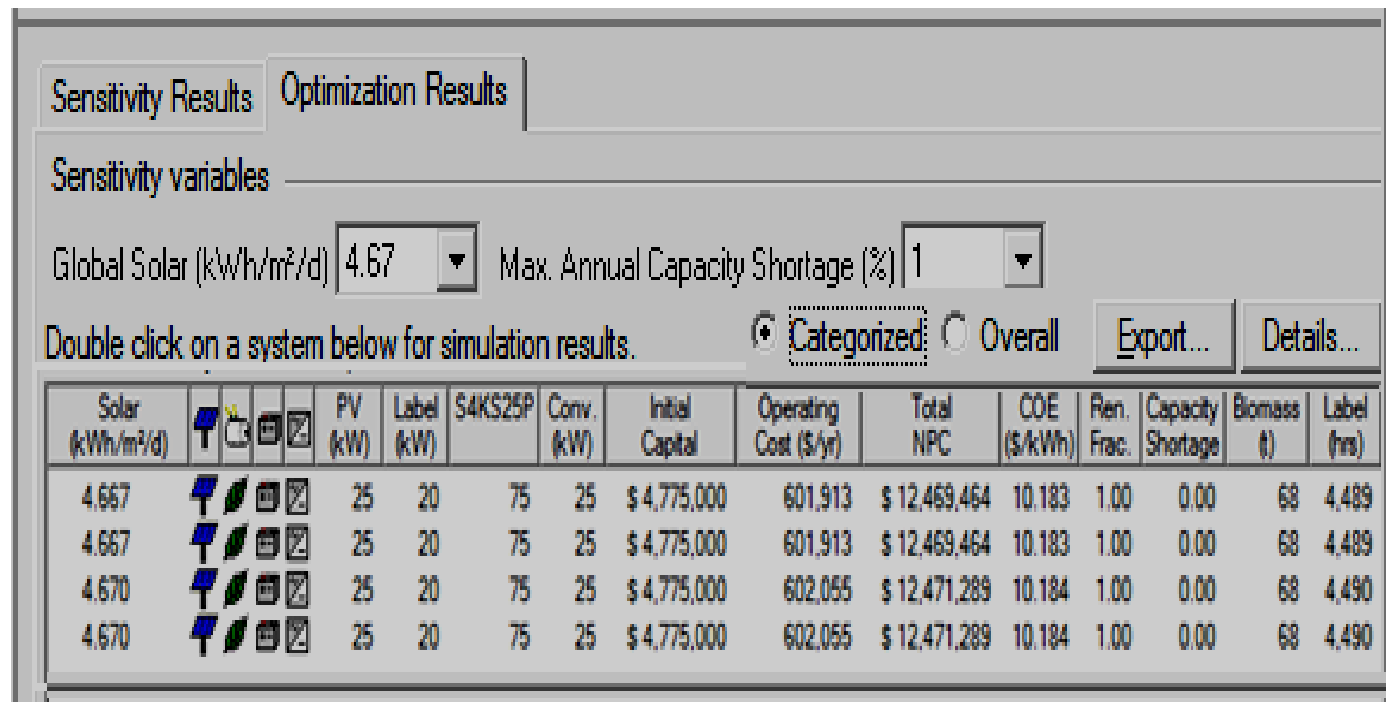

*All the currency values are considered in terms of Tk. (Taka, Bangladeshi Currency) instead of \$(USD).

Figure 8. Optimized result for diesel-PV-wind turbine-battery System.

Sufficient energy can be generated with minimum capacity shortage. In this system, capacity shortage is considered zero. Cost of unit generated of unit generated is 10.183 BDT where as the present cost for solar home system in rural areas is 20 to 25 BDT. Here, the total net present cost is high as Tk. 12,469,464. As project lifetime is considered for 25 years, and if the project run another 25 years at that time the investment will be around $50 \%$ less due to use of existence equipments. Therefore, for reasonable unit price, though the net investment is high considering the life time of project, it hopes that the proposed hybrid model will be commercially viable. In this model, biogas generation is $67 \%$ of total generation and rest 33\% from photovoltaic generation. Ac primary load is $93 \%$ and rest $7 \%$ is deferrable load. Overview of electrical parameters is shown in Figure 9. 


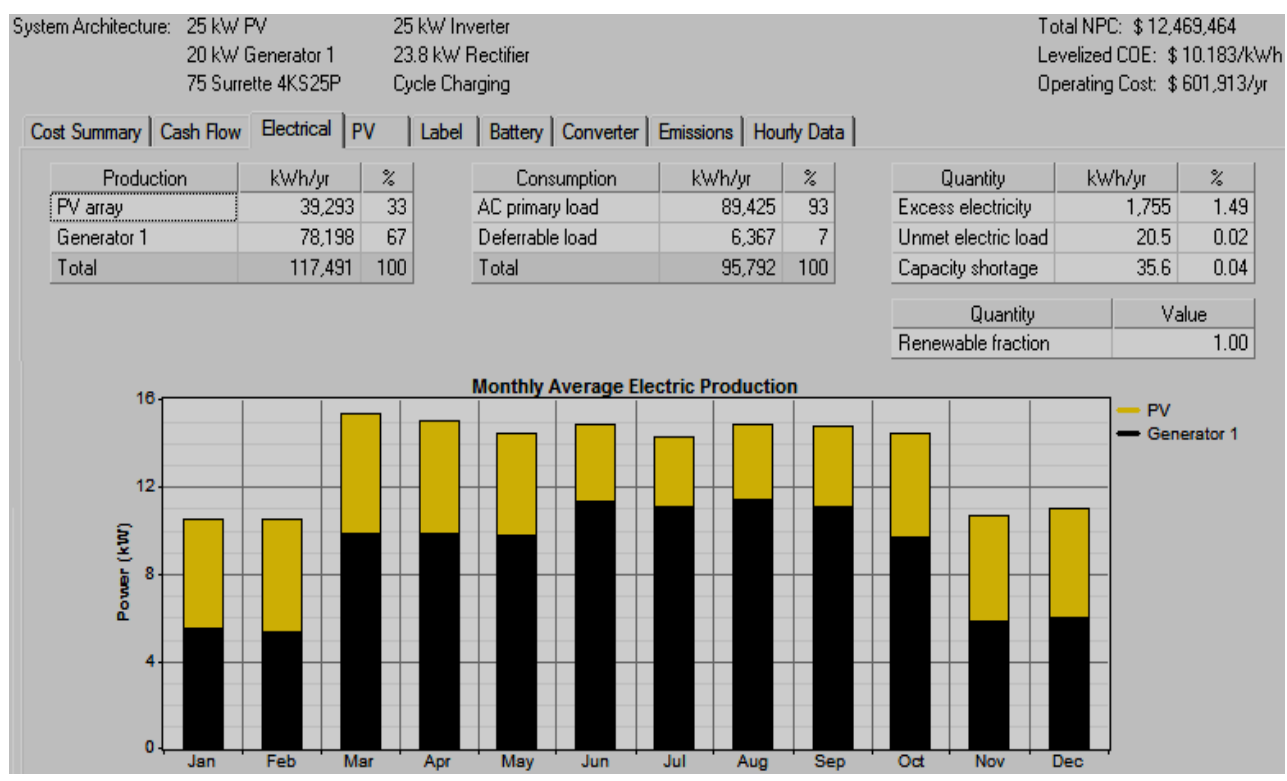

Figure 9. Electrical Parameters obtained from HOMER

\section{Conclusion}

Bangladesh is running in the crisis zone of power shortage. Socio-economic development is stack into a point for the power crisis. Education is the backbone for the development of a nation. There is a great difference in educational level in rural and urban areas in Bangladesh due to lack of electricity in rural area. In Bangladesh nearly $60 \%$ people in rural area have no access to the national grid and around 75\% Bangladesh's 161 million citizens live in rural areas. Without electrification of rural area, it is impossible to connect the peoples of those areas to the main stream of development. Therefore, to solve the power crisis at rural area is an emerging need.

In this paper for electrification of rural area, a village in a remote district of Barisal is chosen. The potentiality of solar and biomass is analysed. Then, based on this potential, a feasibility study for a model community of 100 families and 10 shops has been conducted. The optimize hybrid system was developed considering manufacturing cost and efficiency. The unit price of electricity of the proposed model is around 10BDT with a net present cost is around 12,469,464BDT. Though the proposed system is designed considering a model community, the system can be implemented for any community and at any place in Bangladesh. For reasonable unit price, though the net investment is high considering the life time of project, it hopes that the proposed hybrid model will be commercially viable and will be a guideline for electrification of other rural areas in Bangladesh.

\section{REFERENCES}

[1] M. Ahiduzzaman, (2007) "Rice Husk Energy Technologies in Bangladesh" Agricultural Engineering International: the CIGR Ejournal. Invited Overview No. 1. Vol. IX.

[2] M. S. Islam and T. Mondal, (2013) "Potentiality of Biomass Energy for Electricity Generation in Bangladesh." Asian Journal of Applied Science and Engineering, vol. 2, no. 2, pp.103-110.

[3] G. M. Shafiullah, and M. T. Amanullah, (2010) "Economic analysis of hybrid renewable model for subtropical climate.’Int. Journal of thermal and Environmental Engineering; 1:57-65.

[4] J. Waewask, M. Mani, P. Buaphet and P. Panichayunon, (2007) “A Biomass Gas Engine System for Power Generation of OTOP Building in Southern Thailand," International Conference on Clean Electrical Power, ICCEP '07, pp. 415-422. 
[5] M. R. Nouni, S. C. Mullick and T. C. Kandpal, (2007) "Biomass gasifier projects for decentralized power supply in India: A financial evaluation,” Energy Policy, vol. 35, pp.1373-1385.

[6] K. Q. Nguyen, (2005) "Long term optimization of energy supply and demand in Vietnam with special reference to the potential of renewable energy," Germany: University of Oldenburg.

[7] A. H. Mondal and M. Denich, (2010) "Hybrid system for decentralized power generation in Bangladesh," Energy for Sustainable Development; 14:48-55.

[8] S. M. Shaahid and El-Amin, (2009) "Techno economic evaluation of off-grid hybrid photovoltaicdiesel-battery power system for rural electrification in Saudi Arabia- a way forward for sustainable development," Renew Sustain Energy Rev 13, pp. 625-33.

[9] M. A. Saaklayen, M. M. Rashid, S. Sharmin and A. Haque, (2013) "Integrated Analysis of Hybrid System for Electrification of Island in Bangladesh." Canadian Journal on Electrical and Electronics Engineering, vol. 4, no. 1, February.

\section{Authors}

Md. Raju Ahmed was born in Bangladesh on October 1980, and received B. Sc. from Chittagong University of Engineering and Technology, M. Sc. from Bangladesh University of Engineering and Technology, and Dr. Engg. degree from the University of Tokyo in 2003, 2006 and 2013 respectively, all in Electrical and Electronic Engineering. He joined Dhaka University of Engineering and Technology, Bangladesh, in 2004, and has been an associate professor since 2013. Dr. Ahmed is a member of Institution of Engineers, Bangladesh (IEB).

Subir Ranjan Hazra was born in Barisal, Bangladesh on $25^{\text {th }}$ July, 1985. Currently he is pursuing his post graduate study under the department of Electrical \& Electronic Engineering (EEE) in Dhaka University of Engineering and Technology, Bangladesh. He obtained his B. Sc Engineering Degree in Electrical and Electronic Engineering from Stamford University, Bangladesh in 2008. His research interests include Power System and Renewable Energy.

Md. Mostafizur Rahman was born in Bagerhat, Bangladesh on $20^{\text {th }}$ January, 1981. Currently he is pursuing his post graduate study under the dept. of Electrical \& Electronic Engineering (EEE) in Dhaka University of Engineering and Technology, Bangladesh. He received the B. Sc Engineering Degree in Electrical and Electronic Engineering from the same University in 2006. Currently he is working as a Deputy Manager, System Operations, Teletalk Bangladesh Ltd. His research interests include Digital Communication and Renewable Energy. He is a member of Institution of Engineers, Bangladesh.

Rowsan Jahan Bhuiyan was born in Gazipur, Bangladesh on $13^{\text {th }}$ January, 1983. Currently she is pursuing her post graduate study under the dept. of Computer Science \& Engineering (CSE) in Dhaka University of Engineering and Technology, Bangladesh. She received the B. Sc Engineering Degree in Computer Science \& Engineering from the same University in 2008. Her research interests include DBMS, SQA and Renewable Energy. She is a member of Institution of Engineers and Bangladesh and Bangladesh Computer Council.
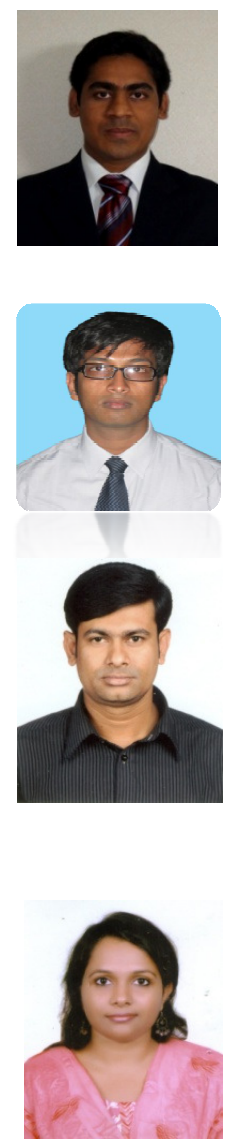